\title{
RAÇA, GÊNERO E SEXUALIDADE NO CONSELHO TUTELAR DE JUAZEIRO/BA
}

\author{
Sérgio Pessoa Ferro ${ }^{1}$
}

\section{RESUMO}

O trabalho estuda a agência do Conselho Tutelar em casos que abordam o tema da diversidade sexual/de gênero na cidade de Juazeiro, situada no Vale do São Francisco, sertão da Bahia. Em que medida a instituição regula a produção do gênero e da sexualidade de crianças e adolescentes sujeitos(as) a sua proteção integral? De base qualitativa, o estudo faz uso dos métodos de análise de documentos e revisão bibliográfica. $\mathrm{O}$ acervo documental é composto por quatro relatórios de atendimento do Conselho Tutelar e do Centro Especializado de Assistência Social no qual figuram crianças e adolescentes identificadas como sexo-gênero dissidentes.

Palavras-chave: conselho tutelar; pessoas sexo-gênero dissidentes; afrocentricidade; colonialismo; direito das crianças e adolescentes.

\section{RACE, GENDER AND SEXUALITY IN THE TUTELAR COUNCIL FROM JUAZEIRO / BA}

\begin{abstract}
The paper studies the agency of the Guardianship Council in cases that deal with the theme of sexual / gender diversity in the city of Juazeiro, located in the Valley of the São Francisco, Bahia. To what extent does the institution regulate the production of gender and sexuality of children and adolescents subject to their full protection? On a qualitative basis, the study makes use of the methods of document analysis and bibliographic review. The documentary collection consists of four reports of assistance from the Guardianship Council and the Specialized Center for Social Assistance in which children and adolescents identified as sexgender dissidents are included.
\end{abstract}

Key-words: tutelar council; gender-dissident people; afrocentricity; colonialism; rights of children and adolescents.

\section{Introdução}

Essa escrita é uma reescrita do direito, da teoria dos direitos humanos, dos direitos da criança e do adolescente elaborados historicamente pelos brancos heterossexuais ricos. Ela

\footnotetext{
${ }^{1}$ Advogado, cineasta e pesquisador na área de direitos humanos. Mestre em Ciências Jurídicas pela Universidade Federal da Paraíba, na linha de Gênero, Sexualidade e Direitos Humanos.
} 
quebra silêncios. Desorganiza, bagunça o normativismo. Sendo ela mesma uma escrita errante, que aceita os riscos de um processo de criação teórica que se desafia a romper com uma tradição de pensamento colonizadora que nunca foi rompida em nossas vidas (MOMBAÇA, 2016).

Em Juazeiro/BA, crianças e adolescentes são acionadas(os) pelo conselho tutelar em virtude de apresentarem comportamentos contrários aos papéis de gênero centrados na heterossexualidade. O conceito de normalização vem de Foucault (2010), na esteira de Canguilhem no estudo do normal e do patológico, e diz respeito à articulação das técnicas de normalização sobre os corpos empreendidas pelas sociedades modernas com seus aparelhos biopolíticos e disciplinares. A norma normalizadora opera nas subjacências das operações jurídicas, ela é pressuposta, mas não nomeada pela lei. Ela é a normatividade do jurídico, o seu extra, o seu fora.

Essa publicação corresponde a um recorte de minha pesquisa para dissertação de mestrado, voltada para análise do discurso e práticas discursivas do conselho tutelar de Juazeiro/BA, na abordagem de casos em que figuram crianças e adolescentes identificadas como sexo-gênero dissidentes. No referido trabalho elaboro uma história social e jurídica da realidade de crianças e adolescentes pretos(as), indígenas e mestiços(as) no Brasil, localizando o nascimento de um domínio específico no direito, o menorismo, no contexto pós-abolição formal da escravidão e independência política da metrópole portuguesa.

Por meio de uma análise dos elementos verbais e não-verbais registrados em matérias de jornais locais, reconstruo o contexto político de Juazeiro no qual foram tramadas as cenas da reforma da infância e juventude nos anos 1980, programada como estratégia para uma política desenvolvimentista de reordenação do Vale do São Francisco. Higienizar as ruas, moralizar as condutas, salvar crianças e adolescentes negros(as), vistos(as) como futuros(as) delinquentes.

Por fim, a partir de um levantamento de dados colhidos em relatórios e dossiês, diário de campo e debate bibliográfico procurei ambientar o conselho tutelar, sua legislação fundadora, infraestrutura, sujeitos e relações de poder internas. Esta publicação direciona nosso olhar para dentro das paredes do conselho tutelar de Juazeiro, espirra ao vasculhar seus arquivos empoeirados em busca dos rastros deixados pelos discursos que articulam suas práticas de heteronormalização e racialização dos corpos, gêneros e sexualidades das famílias negras moradoras das periferias em nome do princípio da proteção integral. 
Metodologicamente essa pesquisa se baseou num referencial não ortodoxo, distante das doutrinas cansadas, descentralizando a lei no processo de interpretação. A legislação é uma linha costurada na malha de enunciados extraídos de relatórios de atendimentos. Um referencial que escapa à leitura do direito positivo, que é apagado pelo texto abstrato da lei.

Fizemos um trabalho de colagem, com o objetivo de montar um mosaico sobre a realidade de crianças e adolescentes de cor, identificadas(os) como sexo-gênero dissidentes e acionadas(os) pelo conselho tutelar em Juazeiro/BA. Partimos de uma orientação epistemológica afrocentrada para pensar por quê crianças e adolescentes lidas(os) como desviantes das regras patriarcais do ser homem-mulher são identificadas(os) como problema no conselho tutelar, quando acionado pela escola ou familiares em busca de uma suposta cura.

A maior parte do material foi levantado em 2013, quando traçava os primeiros contornos dessa pesquisa para o trabalho de conclusão do curso de graduação. Na ocasião, investigava a enunciação das subjetividades dos(as) assistidos(as) pelos equipamentos do sistema de garantia de direitos; na atual proposta, foi feito um recorte institucional no conselho tutelar e temático dirigindo a análise para a perspectiva interseccional de raçaclasse-gênero-sexualidade.

Em 2016, retornei ao campo em busca de mais procedimentos nos quais figuravam crianças e adolescentes dissidentes no gênero/sexualidade, também de uma experiência mais completa na observação das interações. Reuni um acervo composto por relatórios semestrais e dossiês do conselho tutelar que tratam de dissidências de comportamento. Faço referência também a dossiês do centro de referência especializado de assistência social - CREAS, para tratar de casos encaminhados a esta instituição pelo conselho.

Avaliaremos um conjunto de dossiês que expressam a agência do conselho no controle social dos hábitos das famílias negras pobres de Juazeiro/BA. No geral são situações de violação de direitos em que a instituição termina por reproduzir as violências. Não estamos mais no âmbito da investigação da culpa, mas da investigação do(a) sujeito(a). Inferiorização da infância e adolescência negra.

Até onde podemos confiar no direito branco como ferramenta de emancipação social para crianças e adolescentes negros(as) e indígenas que destoam da imagem eurocêntrica de infância, diante de um histórico sempre presente da política menorista - inventada logo após a abolição formal da escravidão para reprimir as juventudes negras nas grandes cidades?

Qual a abordagem do conselho tutelar de Juazeiro/BA quando acionado em função 
de violação de direitos de crianças e adolescentes identificadas(os) como dissidentes de gênero/sexualidade? Tentaremos responder essa pergunta atravessando o labirinto raçagênero-sexualidade-classe.

Analisaremos o modo de reprodução das violências de gênero e sexuais no discurso e práticas discursivas do conselho tutelar de Juazeiro. Reunimos um corpus composto por quatro atendimentos registrados em relatórios, apresentados sob a forma de inquérito, com a identificação do(a) sujeito(a), idade e descrição da demanda. Os nomes foram alterados por questões éticas.

\title{
2. "Menina machão"
}

\author{
Conselho Tutelar \\ Registro: 294/11 \\ Data: 11.07.2011 \\ Nome: Pepê \\ Idade: 11 anos
}

Descrição: Compareceu neste órgão R. C. S., a genitora disse que todas as vezes que foi chamada a comparecer na escola, ela comparecia, a criança disse que esse comportamento sempre foi porque os colegas de classe a chamam de "machão" e não gostava de ser chamada dessa forma, disse que sempre foi desrespeitada pelos funcionários, colegas e a direção [, e que] nunca procurou contar a situação porque sempre fizeram descaso dela mesma, a genitora disse que o gestor Sr. T. não aceita [ilegível]; mas sua filha na escola, com essa situação, a genitora pediu a transferência e a criança está fora da escola.

Em julho de 2011, Pepê, 11 anos, designade ${ }^{2}$ como gênero feminino, foi denunciade ao conselho tutelar em virtude de seu "mau comportamento escolar". Segundo as informações do registro no dossiê da ocorrência, a criança era desobediente em casa e na sala de aula, indiferente às ordens dos adultos.

A genitora da criança a acompanhou no atendimento, demonstrando certa cobrança de seu papel de mãe pela direção da escola, que a interpelava com frequência para abordar a questão da indisciplina. No discurso, as palavras "rebeldia", "agressividade", "indisciplina" vão servir para individualizar o objeto de conhecimento posto à apreciação do conselho na reação violenta da criança aos ataques transfóbicos.

\footnotetext{
${ }^{2}$ Como Pepê transitava entre o masculino e o feminino em sua performance de gênero, escolhemos uma linguagem que não definisse de forma binária a sua identidade.
} 
Pepê responde que sua atitude violenta na escola se deve ao insulto de colegas e funcionários(as) que lhe chamam pejorativamente de "machão". A linguagem inscrita no registro do atendimento não nomeia a violência transfóbica praticada pelas agressões verbais da comunidade escolar.

Judith Butler (2000) elabora o conceito de abjeção para se referir aos processos de subjetivação tocados pela matriz masculinista heterossexual que exclui corpos dissidentes do estatuto de sujeito, classificando-os como seu oposto, sua contradição interna, a negação através da qual ele se afirma.

Os códigos binários de masculino e feminino formam signos de inteligibilidade do humano, do reconhecimento da condição de sujeito, de modo que o não enquadramento a estas categorias engendra processos de exclusão. Ela chama de gêneros inteligíveis aqueles que mantêm relações de correspondência entre o sexo designado em função dos órgãos reprodutivos, o gênero culturalmente construído esperado para aquela anatomia e os desejos sexuais manifestados nas práticas sexuais (BUTLER, 2003).

Corpos que expressam gêneros não inteligíveis, isto é, que não guardam continuidade entre sexo, gênero e sexualidade, como homens trans, travestis, lésbicas, bichas, bissexuais, têm sido colocados historicamente foram do campo da subjetividade jurídica, justamente devido aos processos de abjeção, que negando-lhes a humanidade à medida que os enuncia como estranhos, monstruosos, impedem seu reconhecimento à condição de pessoa.

Chamade de "machão", Pepê era educade para ser uma menina, transitava entre o masculino e o feminino em sua performance de gênero. Homem trans, mulher lésbica, nãobinário; não sabemos como se identificaria se tivesse a liberdade necessária para se autoafirmar em seu discurso perante o conselho tutelar.

A maioria dos(as) professores(as) nas escolas brasileiras não se sentem preparados(as) para lidar com questões de diversidade e temem a repressão das famílias para discutir o assunto nas salas de aula (FERNANDES, 2015). A dissidência de gênero/sexual de Pepê foi tratada como um tabu moral. O discurso do diretor da escola pública Colégio Prof. Artur Oliveira da Silva, por meio do ofício n. 002/2011, por ignorância ou preconceito, silenciou a violação da identidade de gênero, enunciando Pepê como uma criança-problema:

A aluna vem dando muito trabalho aqui no colégio, já chamamos várias vezes os pais para conversarmos, mas sem nenhuma solução, a mesma não respeita alunos, funcionários, professores e nem mesmo a direção do colégio. 
A rejeição do ambiente escolar impede a educação formal de muitas pessoas trans, com o desrespeito aos direitos do uso do banheiro adequado à identidade gênero, ao uso do nome social e o medo constante de poder ser agredida a qualquer momento (PERES, 2009). Ridicularização. Inferiorização. Abjeção.

Pepê foi exposte a uma espiral de violências. Depois de sofrer cotidianamente com o dispositivo escolar armado com piadas ofensivas, desrespeito e exclusão, a direção encaminha a situação ao conselho tutelar, não para reparar seu direito à dignidade, mas para tratar de seu "mau comportamento escolar", "rebeldia", "agressividade", pois vista como um problema sem solução.

O conselho tutelar foi acionado para exercer um monitoramento em torno das possibilidades de subversão sexual e de gênero da criança. Oprimide pela comunidade escolar, a medida tomada foi sua transferência da escola, retirade de seu espaço, de suas memórias, seus afetos. Mais uma negação de direitos para servir a um preconceito. Na escola e no conselho tutelar, Pepê sofreu transfobia/lesbofobia institucional. Primeiro, o bullying, as agressões na convivência escolar; depois a legitimação da violência pelas instituições que se omitiram em mediar o conflito com base na reparação do direito à não discriminação da criança:

\footnotetext{
A transfobia institucional, discriminação empreendida pelas estruturas de poder, é a principal responsável pelo afastamento das pessoas trans dos espaços formais, sendo-lhes negado de forma velada o acesso a direitos humanos e fundamentais, como a educação, o que se faz sentir através do alto índice de "evasão" escolar da população trans e do pequeno número nos cursos de graduação e pós-graduação. (BRITO; ROSÁRIO; ALMEIDA, 2014, p. 06).
}

Não se trata de reprimir os ilícitos, julgar atos infracionais, mas de policiar as expressões de gênero e sexualidade, fiscalizar as condutas, modular os gestos, monitorar as mentes e heteronormalizar os desejos de crianças e adolescentes de cor empobrecidas(os). Este foi o papel do conselho tutelar exercido nesse atendimento, que se insere no contexto das políticas de higienização da cidade através da manutenção de um estado de polícia, um estado de violência subjacente ao estado do direito, sua borda.

A essa reprodução da violência pela instituição chamamos transfobia institucional. Praticada pela escola e pelo conselho tutelar. Vemos um equipamento juridicamente vinculado à proteção dos direitos humanos de crianças e adolescentes agindo violentamente contra sua 
dignidade, negando seu acesso à educação, à identidade de gênero, à personalidade. Biopolítica ou necro-política? Nossas vidas sexo-gênero dissidentes, negras, indígenas, terceiromundistas importam?

Uma das estratégias de permanência na escola elaboradas por crianças e adolescentes sexo-dissidentes é a assumpção de sua identidade de gênero/orientação sexual (FERREIRA; FERREIRA, 2015). Sair do armário: quando elas se afirmam "sou sapatão", "sou bicha", "sou trans", ocupam um território, criam laços recíprocos de empatia com colegas que assim também se reconhecem, formam grupos, problematizam as situações de preconceito e as afrontam.

Abrir os currículos para propostas pedagógicas transviadas, romper com a tradição colonizadora disciplinar violenta mortífera de escolarização do corpo, produção da masculinidade e feminilidade cis-heterossexual pela escola (LOURO, 2009). Essa pauta já vem sendo tocada pelos movimentos LGBT. Em 2011, a bancada fundamentalista cristã conseguiu pressionar a presidenta a vetar a circulação dos kits anti-LGBTfobia nas escolas públicas, com materiais educativos referentes ao programa Brasil Sem Homofobia. Estamos em guerra. E é pela sobrevivência na colônia globalizada genocida heterocapitalista cisembranquecida.

\section{3. "Assédio moral"}

Conselho Tutelar

Registro: $251 / 15$

Data: 04/09/2015

Nome: Leci

Palavra chave: Assédio moral

Descrição: Veio até o Conselho Tutelar, o Sr. A. M. F., genitor da criança acima, juntamente com o casal K. S. S. e F. S. P., onde a criança ficou para os estudos devido à carência de escola na região onde moram. A sra. K. detectou no celular da adolescente umas mensagens fora do comum, de uma outra adolescente de 17 anos, de nome M. C., filha de D. e a mãe é M., residente no S. P. Onde a referida adolescente já é mãe de um filho de um ano. Então foi encontrado várias mensagens no celular de A. de forma amorosa e comprometedora, como também com promessas de presentes e marcando encontro. E as mensagens são justamente em horário escolar e à noite em horários depois que a sra. $\mathrm{K}$. vai dormir. Como também foram apagadas outras mensagens que não tiveram conhecimento. Depois que a senhora K. detectou as mensagens e segurou o celular de A., ela parou de enviar as mensagens porque soube que ela pegou o celular. Mas ainda mandou uma mensagem dizendo: diga a essa K. que me ligue. Então achei 
muito fora do comum e foi notificada a adolescente para vir ao conselho tutelar no dia 10/09/2015, às 09:30h.

Nesse atendimento, o conselho tutelar foi acionado pelo pai da adolescente Leci em virtude de ter encontrado em seu aparelho celular mensagens consideradas suspeitas, comprometedoras, amorosas enviadas por outra adolescente. Leci teve seu telefone apreendido, vasculhado e sua intimidade levada a conhecimento da instituição.

O conselheiro que realizou o atendimento classificou a demanda como "assédio moral", invisibilizando a lesbofobia praticada pela família e reiterando a violência no nível institucional. Leci, adolescente negra, moradora da zona rural, onde não tinha acesso à escola, foi morar na sede municipal de Juazeiro para estudar, na residência de um casal heterossexual amigo da família. Acompanhado desse casal, o genitor se dirigiu ao conselho tutelar em busca de uma atitude disciplinadora sobre a sexualidade de sua filha.

Nesse atendimento, novamente a dissidência sexual não é nomeada. Para se referir ao conteúdo lésbico da conversa entre as adolescentes, o termo enunciado é "mensagens fora do comum”. Essa enunciação pejorativa da subjetividade lésbica a coloca no campo do desvio, do incomum, do anormal, do abjeto. O conselheiro, por despreparo ou conivência, inscreve uma sexualidade dissidente sobre o corpo da adolescente assistida.

O que é o comum? O comum é a heteronorma, o comportamento heterossexual. Butler (2003) fala de uma heterossexualização do desejo, forçada, repetida pela matriz heteronormativa de nossas relações sociais. O normal é o heterossexual, é o princípio de organização da cultura, de distribuição dos papéis assimétricos de gênero.

Afirmamos que a matriz estrutural do conselho tutelar é heteronormativa na medida em que o conselheiro, no discurso do atendimento em análise, enuncia a experiência lésbica da adolescente para fora do campo do normal, do comum, do ordinário e a desqualifica para uma existência abjeta.

A heteronormalidade assegura a reprodução das relações no capitalismo. Ela opera por meio de procedimentos tecnológicos de inscrição dos papéis e práticas sexuais atribuídas ao masculino e ao feminino, inscrevendo nos corpos os códigos que asseguram a exploração de um gênero sobre o outro, de modo que a diferença entre os gêneros corresponde a uma heterodivisão do corpo (PRECIADO, 2014).

A colonização portuguesa trouxe nas caravelas seu patriarcado como modelo hegemônico da família branca escravocrata e a heterossexualidade compulsória como dogma 
reprodutivo. Adrienne Rich (2010) pontua que a norma heterossexual para as mulheres estabelece um mecanismo de garantir o direito masculino de acesso físico, econômico e afetivo a elas.

Leci foi interpelada pelo conselho tutelar em razão de seu genitor, representante da moral heterossexual familiar, encontrar indícios de um possível relacionamento lésbico com outra adolescente. A função repressora, de vigilância e controle social a respeito do conselho tutelar no imaginário das famílias assistidas é tão viva que elas se apropriam do serviço para entregar suas filhas lésbicas, fora do comum, anormais à sua inspeção corretiva moralizadora. Se não deu jeito em casa, vamos ao conselho tutelar! E assim os aparelhos que no plano do discurso jurídico protegem a infância e adolescência, continuam funcionando como instâncias de punição.

\section{4. "Comportamento feminilizado"}

Cadastro n.: 1317-CREAS

Data: 07.11.2011

Nome: Jorge

Idade: 09

Problema: Comparece a este centro, a Sra. E., tia materna da criança citada, encaminhada pelo Conselho Tutelar, a referida senhora está responsável pelos quatro filhos de sua irmã, que após a denúncia de negligência, uso abusivo de álcool de outras drogas por parte dos genitores da criança, que se abstém de cuidar dos filhos. Revela que a criança já apanhou muito, inclusive de facão, que seus genitores a humilham, batem na cara e que seu genitor vive dizendo que será homoafetivo, a tia materna nos informa que a criança tem apresentado comportamento feminilizado, manifesta desejo em brincar com bonecas, porém nos informa que trata-se de criança tranquila embora já tenha vivenciado muita violência . Conversamos com a criança, que verbalizou que outro dia $(06 / 11 / 11)$ seus genitores brigaram, entraram em luta corporal, indo parar na delegacia. Verbaliza que já apanhou muito de faca, corda, cinto e que não gosta do seu genitor apenas da genitora". Com lágrimas nos olhos, a criança diz que teve sua genitora presa "por usar o que não presta". Nega que tenha presenciado seus genitores usando droga ilícita. Nos diz ainda que o seu genitor o chamava de pilantra, fato que o deixava muito triste.

Esse atendimento, como o próximo, foi recebido pelo conselho tutelar e encaminhado ao CREAS, devido à maior gravidade da situação de vulnerabilidade social da criança. O CREAS “configura-se como uma unidade pública e estatal, que oferta serviços especializados e continuados a famílias e indivíduos em situação de ameaça ou violação de 
direitos" (BRASIL, 2013). No campo da infância, ele opera mediante a assistência às famílias por meio de visitas rotineiras, denúncias à polícia, ao Ministério Público ou ao conselho tutelar, encaminhamentos às casas de passagem, hospitais, etc.

A comunicação com o conselho é intensa, e não só se desloca do CREAS em direção ao conselho, como procede de forma inversa: conselheiros(as) tutelares - assim como juízes(as) e promotores(as) de justiça - solicitam diariamente aos psicólogos, pedagogos e assistentes sociais, seus pareceres, visitações in loco e atendimentos periódicos às crianças, adolescentes e seus familiares.

Quem procurou o conselho foi uma tia da criança, Jorge, designado como menino, pois vivia temporariamente sob sua guarda, em virtude da dependência química do álcool e negligência por parte dos(as) genitores(as). Um quadro de acentuada vulnerabilidade social, que demandou o afastamento da criança da convivência familiar.

O discurso do atendimento narra uma trajetória de violências homofóbicas praticadas contra o garoto. Na luta pela sobrevivência em situação de pobreza, as famílias negras trabalhadoras moradoras da periferia vivem em constante contato com a violência, como expressa Maria Gabriela Hita (2014). Violência policial fomentada pela política de guerra às drogas, violência pela exploração no trabalho, violência entre vizinhos e violências familiares, sendo essas a introjeção para o espaço privado da casa, para as relações afetivas, das violências vividas no espaço público.

Nos sertões nordestinos a performance masculina se relaciona com a própria imagem áspera, árida, rude da paisagem, de maneira que o homem sertanejo será o macho capaz de enfrentar a dureza da seca, um projeto de virilidade herdado da tradição patriarcalista das famílias de coronéis, que vem se perdendo em face dos processos de modernização, desenvolvimento, urbanização, conquista dos direitos das mulheres, direitos da diversidade e, justamente por isso, vem sendo retomado pela ingerência conservadora (ALBUQUERQUE JR, 2003).

O homem heterossexual, "cabra macho", pai de família, se consolida como principal agente da violência doméstica praticada contra mulheres e crianças. Por apresentar "comportamento feminilizado", "desejo de brincar com bonecas", o pequeno Jorge sofria ataques violentos como resposta corretiva compulsória de adequação ao papel de homem exigido pelo sistema heterossexual de repartição binária dos gêneros.

As famílias são cobradas pela moralidade popular colonizada pelo cristianismo a 
coagir seus(suas) filhos(as) à heterossexualidade. Eu me lembro muito bem das surras que levei de cabo de vassoura por ser uma menino afeminado. Quem se lembra do adolescente assassinado no fim do ano passado pela própria genitora evangélica por ser homossexual? As marcas do gênero e da sexualidade, para as bichas pretas do terceiro-mundo, não são inscritas somente pela medicina, indústria farmacêutica ou pelo consumo da cultura queer.

Elas são marcadas na pele, tapas na cara, surra de facão, corda e cinto, como as sofridas por Jorge, que também era sujeitado a agressões verbais, injuriosas, ofensivas por parte de seu genitor, que dizia que quando crescesse seria "homoafetivo". Certamente, o pai do menino não utilizava esse termo para se referir à homossexualidade, senão expressões mais populares como viado, bicha, baitola, boiola, frango, etc. A palavra "homoafetivo" enunciada no discurso do atendimento devém de uma dobra da instituição numa tentativa de adequação.

Segundo o Relatório da Violência Homofóbica no Brasil 2012, a população LGBT autodeclarada negra (preta e parda) totaliza 40,55\% das vítimas de violência registradas pelo poder público, em detrimento de $26,84 \%$ das brancas (BRASIL, 2012). Ao contrário do sonho queer vivido em alguns países imperialistas em que há educação de qualidade afinada com uma pedagogia da diversidade, além de melhores condições de trabalho, acesso à saúde, previdência e cultura, em nossas sociedades colonizadas a violência se espalha por todos os lados. O corpo da criança negra sexo-gênero dissidente parece ser seu destinatário final.

Jorge foi encaminhado ao apoio psicológico, mantendo o monitoramento de sua situação pelo serviço social. A escuta psicológica atuará como mecanismo de empoderamento, autonomia ou como um comprimido de cura para as tristezas, melancolias e amarguras vividas por Jorge devido ao trauma das violências homofóbicas? Contra as terapias de reorientação sexual, contra os projetos de cura gay, sigamos na luta.

\section{5. "Desejo de beijar mulheres"}

Cadastro n.: 437/05-CREAS

Nome: Sandra

Idade: 09

Problema: a criança relata que tem três irmãos, sendo que um a mãe deu para adoção, o irmão de 19 anos, J. M. M. S., está detido em Salvador, motivo assalto [...]. A genitora mostra-se muito preocupada, pois alega que a filha procura os meninos do bairro para fazer "ousadia", como relata a Sra. V. Diz ainda temer, pois pode acontecer algo mais grave. [...] A criança Sandra foi abandonada na Orla de Juazeiro com seu irmão F. [07 anos], à noite, pois 
ambos haviam fugido de casa, a genitora estava batendo; ficaram com medo e fugiram de casa. [...] Sandra diz que os meninos procuram ela para fazer "ousadia", mas ela não deixa, eu só uma vez a criança J. C. (10 anos) colocou o pênis nas suas pernas. A criança está abrigada na Casa Rosa Menina, e alega não querer voltar para casa, pois ouviu sua genitora falar que não gosta dela, que odeia.

Em março de 2005, Sandra, designada pelo feminino, também foi conduzida ao CREAS pelo conselho tutelar. A menina, desde tal ano vem sendo monitorada por quatro anos pela instituição de forma contínua e ininterrupta. Sandra passou a ser assistida pelo Programa Sentinela, promovido pelo Governo Federal e implementado pelos municípios com o objetivo de combater a exploração sexual de crianças e adolescentes, assegurando-lhes a garantia dos direitos sociais violados mediante o acesso aos serviços de assistência social, saúde, segurança, lazer, cultura, educação e justiça (PINHEIRO, 2007).

O gênero discursivo do relatório do programa estabelece um tom de superioridade, distanciamento hierárquico entre a figura do(a) assistente social avaliador(a), sujeito(a) de conhecimento e seu objeto discursivo, a criança violentada. Vimos que a construção desse lugar de enunciação das instituições de assistência a crianças e adolescentes em Juazeiro seguiu o plano nacional higienista, de ordenação do espaço urbano, reprodução institucional da violência e estereotipação da infância e adolescência negra amarrada à categoria de problema social.

Todo gênero de discurso (relatório, processo, livro, poema, artigo científico, etc.) pressupõe um lugar de enunciação afetado pelo exercício de determinadas capacidades construídas historicamente nas formações discursivas, que reconhecem autoridade à enunciação (MAINGUENEAU, 1997). Logo, a escrita do(a) conselheiro(a) tutelar, do(a) assistente social, do(a) juiz(a) de direito têm que atender a essas normas de enunciação sob pena de seu discurso não ser autorizado por seu campo.

A descrição do problema realizada pelo assistente social, ao invés de centralizar sua narrativa na temática da exploração/abuso sexual para a qual se dirige o programa, assumiu uma indiscreta função de tecnologia do gênero voltada ao exame da sexualidade de Sandra. Respaldado na fala de sua genitora, o discurso do atendimento vai mostrar um corpo feminino exótico, pecaminoso, hipersexualizado pela interseção das violências de raça e gênero que afetam às mulheres negras desde a infância (ARRAES, 2013). A sexualidade de Sandra vai emergir no discurso como selvagem, excitada. Ela quem procuraria os meninos para fazer "ousadias", uma enunciação legitimadora da violência sexual. 
Registro do atendimento psicológico em 15 de março de 2005:

\begin{abstract}
Atendi a criança que veio para o atendimento psicológico, pois ficou abrigada desde sexta-feira, 11.03.2005, na Rosa Menina devido a sua genitora ter ficado muito nervosa com seu serviço e do seu irmão F., de 07 anos de idade, que saíram de casa e foram para a Orla de Juazeiro, pois estavam com medo de levar surra da mãe devido terem desobedecido a mãe, que já tinha pedido para não levar crianças para brincar dentro de casa, pois tomou conhecimento que Sandra estava fazendo ousadia com meninos da rua - ela vai atrás dos meninos, segundo informação da vizinha no Conselho Tutelar.
\end{abstract}

Esse atendimento ocorreu por ocasião do acolhimento de Sandra na casa de passagem Rosa Menina, voltada para o abrigo de crianças e adolescentes do gênero feminino expostas a situação de violação de direitos em Juazeiro, logo após ter fugido de casa com seu irmão por receio de apanhar da genitora, tendo desobedecido sua ordem de não levar outras crianças para lá.

O tom do discurso da psicóloga se assemelha ao do assistente social que abriu o procedimento, destacando a excitação sexual de Sandra. Essa é uma estratégia típica da cultura do estupro reproduzida por nossa sociedade misógina para culpar a mulher pelas situações de violência sexual praticadas pelos homens que as enxergam como objeto a serem conquistado (KOLLONTAI, 2016). Na linguagem machista dessa cultura: ela, culpada, quem procurou, "tava pedindo"; e ele, inocente, é violento por natureza, "pegador", instintivo.

Outro atendimento psicológico, em 14 de outubro de 2009:

Relata, ainda, que quando tinha 10 anos a mãe a oferecia na orla para os homens,
sente muita vergonha dessa atitude da mãe e muitas vezes precisou mentir só porque
a mãe a 'obrigou'. Quando foi falar com o juiz sobre o assédio que sofreu, teve que
falar o caso só pela metade, o irmão já chegou a abusá-la sexualmente, colocou o
pênis no meio das pernas dela, e não foi apenas uma vez. Falou que uma vez já
arrumou um namorado, mas sentiu vergonha e nojo de beijá-lo, alega que devido a
essa vida tão confusa não consegue namorar.

Dois dias depois do dia da criança branca heterossexual rica cisgênero higienizada, comemorado por nosso calendário comercial, Sandra retornava ao CREAS para mais um atendimento psicológico. Já adolescente, com 13 anos, relata uma memória traumatizada pela exploração sexual por parte de sua própria genitora.

Em sua famosa História da Sexualidade, Foucault (1988) questiona a noção repressiva do poder sobre o sexo, oriunda da tradição psicanalítica do recalque. Ao invés de uma proibição às práticas sexuais, o poder, por meio de mecanismos como a psicologia e 
psiquiatria, exerce uma coerção prescritiva, produtiva da (hetero)sexualidade. "Polícia do sexo: isto é, necessidade de regular o sexo por meio de discursos úteis e públicos e não pelo rigor de uma proibição" (FOUCAULT, 1988, p. 31).

Sandra sentiu na pele a violência da heterossexualização compulsória, levada a cabo não só por dispositivos disciplinares (escola, casas de passagem, hospitais) e biopolíticos (serviço social), aos quais tinha um acesso precário, subalternizado, mas pela exploração sexual do seu corpo, a mando de sua própria mãe, frente à vulnerabilidade social e econômica em que viviam.

Chamada a falar sobre sua sexualidade, seu corpo, seus desejos, Sandra revela que sente nojo por homens, que tem vergonha de beijá-los. Ela diz que não se sente confortável para se relacionar com eles devido à sua "vida tão confusa".

16 de outubro de 2009, ficha de acompanhamento do Programa Sentilena:

\begin{abstract}
A Sra. V. chega a este Centro e se mostra bastante fragilizada e sofrida. Nos conta que Sandra [agora com 14 anos] era uma menina de ouro', mas que agora se tornou uma menina ruim. Fala das fugas constantes e que a adolescente vive em companhia de meninos e homens mais velhos, segundo a genitora, ela tem namorado muito com um e com outro e por último manifestou desejo de beijar mulheres.
\end{abstract}

Sandra estava sendo empurrada para o "armário" pela exploração sexual, por um tipo de heterossexualização compulsória designada pelo racismo estrutural que mediava seu contato com a violência. Um duplo armário, conforme a conceituação de Vanilda Maria de Oliveira (2006), o armário da raça e o armário do gênero/sexualidade. Segundo a pesquisadora, “as pessoas LGBT negras podem experimentar a opressão por orientação sexual/identidade de gênero de uma maneira diferente das pessoas que não enfrentam o racismo"(OLIVEIRA, 2006, p. 95).

A imagem de Sandra, que afirmou um desejo bissexual, enquanto mulher promíscua, hipersexualizada, pecaminosa, bissexual apaga a finalidade jurídica conferida ao Programa Sentinela em combater a exploração sexual. Desvio do olhar. Culpabilização da mulher pela violência sexual sofrida, regulação heterossexual de seus prazeres, alinhamento aos papéis patriarcais esperados para o gênero feminino. Policiamento do desejos não heterossexuais e dos corpos não adequados ao binarismo homem-mulher, autorizado pelo próprio sistema de garantia de direitos. 


\section{Considerações finais}

O campo autônomo de tutela da criança e adolescente no discurso jurídico brasileiro nasceu de uma incoerência lógico-estrutural do direito penal, a necessidade de punir se esbarrava nos princípios humanistas dos reformadores. Após a abolição formal da escravidão, no projeto republicano de nação embranquecida o discurso criminal se desfragmentou, expulsando a criança e adolescente criminalizados(as) para um universo científico próprio, com raciocínios e confinamentos específicos.

A exploração do menor desviante, o sequestro de seu corpo por instituições correcionais, disciplinares, repressoras, violentas fundamentava-se no dever de instrução assumido pela dogmática em relação a esses recentes sujeitos, os(as) menores. Nasceu, dessa incongruência científica, o discurso jurídico da menoridade e sua finalidade declarada não era punir, senão instruir, conduzir, aconselhar.

No discurso, o maior seria punido por sua ação ilícita, típica e culpável, a criança seria instruída em virtude dela mesma, de sua falta de consciência, sua incapacidade de conduzir-se conforme a vontade, sua irracionalidade. Ao menor, foi outorgada uma culpa pressuposta que autoriza qualquer intervenção sobre seu corpo ou sua mente.

O Estatuto da Criança e do Adolescente marcou uma ruptura no discurso de infância, com a doutrina da proteção integral e o reconhecimento formal de crianças e adolescentes como sujeitos(as) de direito. A abordagem prática das instituições, no entanto, segue distante das famílias negras empobrecidas, incapaz de superar as situações de violação de direitos.

Em Juazeiro-BA, no fim dos anos 1980, a onda desenvolvimentista do espaço urbano, que reordenava a cidade para receber as empresas exportadoras da agricultura irrigada forjou imagens e enunciados depreciativos da infância e adolescência negra pobre em circulação nos principais jornais locais, expressando subjetividades governáveis, carentes de autoridade e de comando. Trombadinhas, pivetes, menores abandonados. Uma pedra no caminho do progresso. O rosto do subdesenvolvimento.

A reforma antecessora do ECA foi problematizada nessa conjuntura. Muitos seminários foram realizados nesse momento pautando a reforma na assistência a crianças e adolescentes. A pauta criticava as internações e a abordagem policial de menores. Os "menores" se afastavam cada vez mais dos "criminosos", seu método de disciplinamento e seus lugares de expiação se especializavam à medida que suas necessidades se diferenciavam. 
No discurso, menos punição e mais prevenção.

Setores fundamentalistas cristãos se articularam para uma campanha de heteronormalização das condutas, moralização das famílias pobres, salvação da corrupção moral de crianças e adolescentes. Livrá-las do consumo de drogas, da homossexualidade, da promiscuidade sexual.

De acordo com os relatórios de 2010 e 2011 do conselho tutelar de Juazeiro-BA e com dezenas de dossiês datados de diferentes anos que foram examinados, as famílias negras empobrecidas formam o maior público de atendimentos. $\mathrm{O}$ poder que se exerce nos infinitos encaminhamentos do conselho não se preocupa, por conseguinte, com a dignidade e com os direitos humanos da criança e adolescente, senão se reserva a administrar as condições de vida e morte da população negra periférica, mantendo-a sob controle através de seu enquadramento em tipos penais, acompanhamentos assistenciais e monitoramentos.

Os maiores motivos de atendimento, nos referidos anos, de acordo com sua própria legenda, são "negligência materna", "desobediência/rebeldia/indisciplina" e "conflito familiar", conceitos que servem para controlar os hábitos das famílias, criminalizar a mulher negra, moralizar e vigiar crianças e adolescentes.

No processo de escrita não nos isolamos do mundo, tentamos criar uma realidade paralela, sustentada pela teoria do discurso científico, nos deslocar para um lugar de conhecimento superior ao mundo, alheio a ele pela insistência no erro colonizador do pensamento moderno europeu e sua noção de sujeito racional, que nos cega frente aos problemas nos afetam ao nosso lado.

Escrevendo esse texto fui atravessado pelos gritos vindos da casa de uma vizinha, uma mulher negra, mãe solteira, que, sozinha cuida de dois filhos e uma mãe idosa, em gritos: “chama o conselho tutelar pra pagar sua comida, chama o delegado pra pagar sua comida!". As palavras se dirigiam a seu filho. Na luta pela sobrevivência, o imaginário da população negra pobre enxerga o conselho tutelar como equipamento punitivo, repressor, devido a sua ação criminalizadora.

Não só o conselho, como a polícia, o tribunal, as instâncias públicas no geral são espaços de subalternidade, em que as hierarquias raciais são ostentadas. Em nossa sociedade de supremacia branca, o conselho tutelar opera como dispositivo redistributivo das violências raciais, de gênero e sexualidade.

O estatuto da criança e do adolescente é uma promessa jurídica. Um documento 
histórico-cultural produzido pelas nossas elites brancas para se adequar às ordenações internacionais. Como a abolição formal, elas ainda reagiram e reagem à proteção integral dos direitos humanos das crianças e adolescentes negro(as) e indígenas brasileiros(as). As tentativas em reduzir a maioridade penal tenta frear essas conquistas. Isso é só um sintoma da relação histórica entre proteção-criminalidade na infância e adolescência brasileira.

As famílias se apropriam do serviço de tutela para reprimir as condutas de seus(suas) filhos(as) quando dissonantes da moralidade popular cristã. Muitas famílias assistidas acionam o conselho para corrigir posturas consideradas inadequadas das crianças e adolescentes sexo-gênero dissidentes. Acessando o conselho pelo imaginário da correção, há casos em que elas procuram a instituição para "curar" os(as) filhos(as) da homossexualidade, do comportamento afeminado ou masculinizado.

Da análise dos discursos registrados nos atendimentos a crianças e adolescentes sexo-gênero dissidentes, percebemos que as violências que ensejaram a situação de vulnerabilidade são redistribuídas no nível institucional. O tema da diversidade sexual e identidade de gênero é considerado um tabu pelos(as) conselheiros(as) tutelares.

As violências são invisibilizadas. Partindo de uma posição em que a heterossexualidade é pressuposta, exigida compulsoriamente; quando lidam com situações de lesbo-homo-trans-bifobia não sabem identificá-las, naturalizando os preconceitos. Esse silenciamento impossibilita mediar os conflitos LGBTfóbicos e reparar os direitos violados.

A precariedade de infraestrutura do conselho tutelar, a falta de informação sobre a temática por parte dos(as) conselheiro(as) e a formação explicitamente preconceituosa de alguns são empecilhos à adoção de uma política de combate às situações de violência por motivo de LGBTfobia.

As biopolíticas regulatórias do corpo assumem uma função redistributiva da violência sobre os corpos e mentes de crianças e adolescentes negros(as) e indígenas empobrecidas. Redistribuem as violências contra as identidades de gênero e as sexualidades dissidentes. Redistribuem as violências raciais na inferiorização, subalternização e controle das famílias negras periféricas.

Ao invés de fazer viver, deixar morrer. Necropolíticas, como ironiza Jota Mombaça. Policiamento do close. Dar close é dar pinta. Não esconder a potência sexo-gênero dissidente, a subversão do corpo e da subjetividade cis-heterossexual empurrada para o armário pela violência. 
Muitas conquistas foram alcançadas pela a "comunidade LGBT" no Brasil, outras ainda estão no devir. Enquanto as monas brancas aquezadas ${ }^{3}$ podem consumir a cultura queer nos clubes seguros, pagos pelo pink money, as negras periféricas, sertanejas são acionadas pela polícia violenta do gênero e da sexualidade. Uma patrulha heterossexualizadora pelo bem da família. O conselho tutelar.

A atuação pelo povo de santo, população negra e pela diversidade de gênero e sexual no conselho tutelar de Juazeiro por Dona Ioná Pereira Silva me mostrou caminhos para a ocupação dos espaços públicos de governabilidade. Não podemos acreditar na instituição filiada a um Estado que historicamente tem promovido o genocídio da população negra e indígena. E também o genocídio da população sexo-gênero dissidente.

A agência nas instituições precisa ser estratégica. Entrar e sair. Os espaços institucionais são um dos campos de batalha. Ainda temos a rua, a arte e os nossos corpos. "Fora dá pra realizar mais do que dentro", disse Dona Ioná, filha de Oxum. Uma vez dentro, piratearemos as ferramentas em favor de nossa luta, sabotaremos as engrenagens que nos matam. Contrabando jurídico. Apropriação da lei racista heteronormativa para conseguir nossos fins.

O fim é importante, não pode ser perdido. Centrar a agência na melhoria de condições de vida, mais do que sobrevivência, para nossas comunidades. Exigir reparação pela história genocida, reescrevê-la. Reescrever o presente. Mudá-lo. Tombar o humanismo, enterrar o sujeito moderno branco cis-heterossexual rico europeu. Seus problemas de pósmodernismo não são nossos. Nossos problemas são problemas demais e se chocham na colonização reatualizada pelas tecnologias.

É preciso formação em educação para a diversidade, combate ao racismo e à cultura do estupro direcionada aos(às) conselheiros(as) de Juazeiro. Mas é preciso também fazer ruir as velhas estruturas paternalistas coronelistas racistas patriarcais heteronormativas reelaboradas pelo capitalismo neocolonial das fazendas agroexportadoras exploradoras.

Representatividade importa. Ação direta também. A prática anticolonial do direito é possível? O mapa será desenhado pela história do presente. Voltar a um passado pré-colonial é utópico. Permanecer no colonialismo, distópico. Haverá o pós-colonial? Esse texto não conclui. A história não acabou.

\footnotetext{
${ }^{3}$ No bajubá, aqué quer dizer dinheiro. Aquezada: quem tem muito dinheiro.
} 


\section{Referências}

ALBUQUERQUE JR, D. M. de. Nordestino: uma invenção do falo. Uma história do gênero masculino (Nordeste - 1920/1940). Maceió: Catavento, 2003.

ARRAES, Jarid. A sexualidade da mulher negra. Blogueiras Negras. Disponível em: http://blogueirasnegras.org Publicado em: abril 2013. Acesso em: 02 fev 2017.

BRASIL. Secretaria de Direitos Humanos. Relatório sobre violência homofóbica no Brasil: ano de 2011 / Secretaria de Direitos Humanos; Priscila Pinto Calaf, Gustavo Carvalho Bernardes e Gabriel dos Santos Rocha (organizadores). - Brasília, DF : Secretaria de Direitos Humanos, 2012.

BRASIL. Secretaria de Direitos Humanos. Relatório sobre violência homofóbica no Brasil: ano de 2012 / Secretaria de Direitos Humanos; Priscila Pinto Calaf, Gustavo Carvalho Bernardes e Gabriel dos Santos Rocha (organizadores). - Brasília, DF : Secretaria de Direitos Humanos, 2013.

BRITO; ROSÁRIO; ALMEIDA. Biodireito e transgenereidade: a vivência educacional das mulheres trans sob a ótica dos direitos humano. Anais do V Encontro Nacional de Pesquisa e Extensão em Direitos Humanos e Fundamentais da UESC, 2014.

BUTLER, Judith. Corpos que pesam: sobre os limites discursivos do "sexo". In: LOURO, G. L. (Org.) O corpo educado. Traduções de Tomaz Tadeu da Silva. Belo Horizonte: Autêntica, 2000 .

BUTLER, Judith. Problemas de gênero: feminismo e subversão da identidade. Tradução de Renato Aguiar. Rio de Janeiro: Civilização Brasileira, 2003.

HITA, Maria Gabriela. A casa das mulheres n'outro terreiro: famílias matriarcais em Salvador. Salvador: EDUFBA, 2014.

KOLLONTAI, Verinha. A cultura do estupro da sua origem até a atualidade. Blog Feminismo Sem Demagogia. Disponível em:

https://feminismosemdemagogia.wordpress.com/2016/06/23/a-cultura-do-estupro-da-sua-orig em-ate-a-atualidade/ Acesso em: 07 mar 2017.

LOURO, G. L. Heteronormatividade e homofobia. In: JUNQUEIRA, R. D. (Org.).

Diversidade sexual na educação: problematizações sobre a homofobia nas escolas. Brasília: Ministério da Educação, Secretaria de Educação Continuada, Alfabetização e Diversidade, UNESCO, 2009.

MAINGUENEAU, Dominique. Novas tendências em análise do discurso. Tradução de Freda Indursky. Campinas: Editora da UNICAMP, 1997.

MOMBAÇA, Jota, Jota. Rastros de uma Submetodologia Indisciplinada. Revista

Concinnitas, ano 17, volume 01, número 28, setembro de 2016.

FERNANDES, Marcela. Escolas não estão preparadas para combater homofobia, dizem 
especialista. Geledés. Disponível em: http://www.geledes.org.br/escolas-nao-estaopreparadas-para-combater-homofobia-dizem-especialistas/ Acesso em 01 mar 2017.

FERREIRA; FERREIRA. Vivências escolares de jovens homossexuais afeminados. Tópicos Educacionais, Recife, n.2, jul/dez. 2015.

FOUCAULT. História da sexualidade I: a vontade de saber. Tradução de Maria Thereza da Costa Albuquerque e J. A. Guilhon Albuquerque. Rio de Janeiro: Edições Graal, 1998.

FOUCAULT. Os anormais. Tradução de Eduardo Brandão. São Paulo: Editora WMF Martins Fontes, 2010.

OLIVEIRA, Vânia Maria de. Um olhar interseccional sobre feminismos, negritudes e lesbianidades em Goiás. Dissertação (Mestrado em Sociologia). Goiânia: UFG, 2006.

PERES, W. S. Cenas de exclusões anunciadas: travestis, transexuais, transgêneros e escola brasileira. In: JUNQUEIRA, R. D. (Org.). Diversidade sexual na educação:

problematizações sobre a homofobia nas escolas. Brasília: Ministério da Educação, Secretaria de Educação Continuada, Alfabetização e Diversidade, UNESCO, 2009.

PINHEIRO, R. R. L. M. P. Violência sexual infanto-juvenil em Natal: uma avaliação do Programa Sentinela. Dissertação (Mestrado em Serviço Social). Programa de Pós-Graduação em Serviço Social, Natal, 2007.

PRECIADO, Paul. Manifesto contrassexual. Tradução de Maria Paula Gurgel Ribeiro. São Paulo: N-1 Edições, 2014.

RICH, Adrienne. Compulsory Heterosexuality and Lesbian Existence. In: GELP, Barbara C. \& GELP, Albert (editores). Adrienne Rich's Poetry and Prose. New York/London: W.W. Norton \& Company, 1993.

\section{Documentos Conselho Tutelar e CREAS}

JUAZEIRO. Conselho tutelar. Relatório de atendimentos 2010.

JUAZEIRO. Conselho tutelar. Relatório de atendimentos 2011.

JUAZEIRO. Conselho Tutelar. Dossiê n. 294/11. Data: 11.07.2011. Criança: J. S. S. Idade: 11 anos.

JUAZEIRO. Conselho Tutelar. Dossiê n. 251/15. Data: 04.09.2015.

JUAZEIRO. Centro Especializado de Assistência Social - CREAS. Registro n. 1317, novembro de 2011.

JUAZEIRO. Centro Especializado de Assistência Social - CREAS. Registro n. 437, março de 2005 . 